\title{
Growth Hormone Therapy for Short Children Born Small for Gestational Age
}

\author{
P. Chatelain ${ }^{a} \quad$ A. Carrascosa ${ }^{b} \quad$ G. Bona ${ }^{c} \quad$ A. Ferrandez-Longas ${ }^{d}$ W. Sippell \\ ${ }^{a}$ Service d'Endocrinologie et Diabétologie Pédiatrique, Hôpital Debrousse, Lyon, France; ${ }^{b}$ Department of \\ Paediatrics, Hospital Materno-Infantil Vall d'Hebron, Barcelona, Spain; ' Unit of Paediatrics, Department of \\ Medical Sciences, University of Piemonte Orientale 'A. Avogadro', Novara, Italy; ${ }^{d}$ Endocrinology Unit, \\ University Children's Hospital Miguel Servet, Zaragoza, Spain, and ${ }^{\mathrm{e}}$ Division of Paediatric Endocrinology and \\ Diabetology, University Children's Hospital, Kiel, Germany
}

\section{Key Words \\ Recombinant human growth hormone therapy • Safety considerations, growth hormone therapy • Small-for-gestational-age children}

\begin{abstract}
Children born small for gestational age may demonstrate continued growth retardation, resulting in persistent short stature. In the majority of the cases, this is linked with abnormal growth hormone secretion and also abnormal insulinlike growth factor levels. This review discusses the treatment of such children with recombinant human growth hormone. It illustrates the importance of starting therapy early, the dose-dependent response, and the advantages of continuous therapy and describes safety considerations.
\end{abstract}

Copyright $\odot 2007$ S. Karger AG, Basel

\section{Introduction}

It is estimated that approximately $3-5 \%$ of the neonates are born small for gestational age (SGA) [1]. Definitions of fetal growth failure or fetal growth restriction based on birth data vary and have included a birth weight of less than $2.5 \mathrm{~kg}$, a ponderal index of less than -2 stan- dard deviations (SD), and birth weight or length on growth charts of less than the third, fifth, or tenth percentile for gestational age. At an advisory board meeting in 2001, the members of the International SGA Advisory Board Consensus Development Conference concluded that children who are born with a weight or length of \pm 2 SD scores (SDS) are appropriate for gestational age (AGA). Therefore, SGA should be defined as a weight and/or length of less than or equal to -2 SDS below the mean for gestational age [2]. This conclusion was recently endorsed at a consensus meeting of the International Societies of Paediatric Endocrinology and the Growth Hormone Research Society [3].

The term SGA is often inaccurately used interchangeably with the expression intra-uterine growth retardation (IUGR) [4, 5]. IUGR refers to insufficient fetal growth identified either in utero by diminished size markers (measured by ultrasonography or X-ray) or at birth by length and weight compared with gestational age standards [6-8]. In daily practice, IUGR describes a pathophysiological condition of inhibited fetal growth in utero, whereas SGA refers to a statistically defined condition at birth, regardless of the cause. Moreover, neonates with IUGR are all born SGA, but not all infants who are SGA have experienced IUGR.

\section{KARGER \\ Fax +41 613061234 \\ E-Mail karger@karger.ch}

www.karger.com

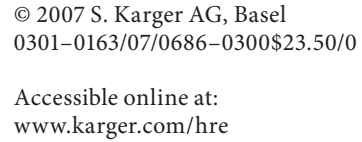

Pierre Chatelain

Service d'Endocrinologie et Diabétologie Pédiatrique

Hôpital Debrousse

FR-69322 Lyon Cedex 05 (France)

Tel. +33 472385 601, Fax +33 472385 500, E-Mail pierre.chatelain@chu-lyon.fr 


\section{Catch-Up Growth and Adult Height Normalization Are the Normal Postnatal Growth Patterns}

Most infants who are born SGA achieve a normal height following a period of catch-up growth before the age of 2 years [9]. This accelerated growth can lead to a weight or height within 2 SDS for age. Nevertheless, approximately $10-15 \%$ of the infants who were born SGA fail to achieve catch-up growth, and those who do not achieve this within 2 years have a high risk of short stature in later life [10-12]. Additionally, the extent of catchup growth usually affects the adult size independently of postnatal growth failure in some people whose size remains below the lower limit of the normal range.

Several studies have demonstrated the persistence of short stature in people who were born SGA. These data reflect the importance of catch-up growth during infancy in achieving height within the normal range. Among a cohort of 3,650 healthy neonates, including 198 (5.4\%) who were born SGA, 13.4\% of those born SGA remained short in stature (less than -2 SDS in height) after 1 year, although during later childhood, approximately half of these children achieved a normal height [11]. By the age of 18 years, 7.9\% (289) of the adults born SGA remained short in stature.

In a study performed in The Netherlands [10], approximately $15 \%$ of 724 infants who were born SGA (including 423 born prematurely) failed to manifest sufficient catch-up growth to achieve a normal height within the first 2 years of life [10]. Interestingly, the proportion of infants who failed to catch up sufficiently did not differ significantly between infants who were born SGA prematurely and infants who were born SGA at full term.

A long-term French study on adolescents (mean 12.8 years) with a short stature who were born SGA [13] demonstrated that spontaneous catch-up growth between the onset of puberty and adult height was only about $0.5 \mathrm{SD}$, despite a 2-year delay in bone age at pubertal onset. Furthermore, another study performed in France [14] demonstrated that, by the age of 22 years, individuals born SGA had a significantly reduced body size and a higher frequency of short stature than those born AGA. An adult height of less than 2.5 SDS was observed in $3.7 \%$ of the patients in the SGA group.

When discussing SGA with the parents, the paediatrician can estimate that the child has about a $90 \%$ chance of demonstrating spontaneous catch-up by the age of 3-4 years. For those children who have not shown catch-up growth by this age, there is a high risk that the child will remain short in stature (less than or equal to $-2 \mathrm{SD}$ ) into adulthood.

\section{Growth Hormone (GH), Insulin-Like Growth Factors (IGF), and Catch-Up Growth}

In healthy people, GH and IGF interact to regulate growth. In utero, IGF-I, IGF-II and insulin are the key factors in regulating fetal growth, with GH having little effect [15-17]. Postnatally, the contribution of IGF-I becomes more important than that of IGF-II, and neonates with growth restriction have lower IGF-I levels than neonates with a normal growth. Although children with a congenital GH deficiency are born with a relatively normal weight and length, they can develop severe early postnatal growth failure [15]. Postnatally, the serum levels of GH correlate with the IGF-I levels, and infants with GH deficiency, therefore, have decreased levels of IGF-I as compared with those with normal GH levels. Importantly, it has been reported [18] that a high endogenous GH secretion significantly increases the IGF-I levels in short GH-sufficient neonates born SGA at 3 days postnatally as compared with AGA controls. This is evidence for a functionally activated GH-IGF-I axis in SGA neonates [18].

Several studies have shown that growth failure in patients born SGA who fail to manifest catch-up growth is linked to abnormal GH, IGF-I, and insulin levels [19-21]. Approximately $60 \%$ of the children with a persistent short stature who were born SGA have an abnormal GH secretion and reduced IGF levels [19]. Although children with a short stature who were born SGA frequently have GH levels lower than normal, most are not usually classified as being $\mathrm{GH}$ deficient by recognized criteria. Indeed, the precise impact of the GH secretion status on a persistent short stature remains difficult to assess, with no clear discernible relationship between GH, IGF-I, or IGF-binding proteins and spontaneous catch-up growth $[10,22,23]$.

\section{SGA Is Associated with Non-Growth Correlates: Evidence for a Hormonal Resistance State?}

Adult metabolic syndrome is a disease, in which conditions such as insulin resistance, hypertension, glucose intolerance, central obesity, and dyslipidaemia are commonly co-present, leading to an increased risk of cardiovascular disease. Although for a long time a controversial issue, there is now evidence for an increased prevalence of metabolic syndrome among adults who were born SGA [24-27], and it is, therefore, important that their height, weight, and body mass index are closely monitored to prevent excessive weight gain, as children born 
SGA who catch up in weight and height are at a higher risk than those without catch-up [27]. The relative risk of developing metabolic syndrome as an adult is greatest in those with catch-up growth, but is still greater in those without catch-up growth as compared with AGA neonates. The presence of insulin resistance in SGA requires improved understanding, but raises the question of hormonal resistance underlying the SGA condition throughout life [12, 28].

In summary, SGA is associated not only with shorter than average height, but also with potential health disadvantages, such as reduced body fat and a lack of appetite as compared with individuals who were not born SGA; there is also an increased prevalence of metabolic disorders in later life among patients born SGA as compared with those born AGA.

\section{Psychosocial Impact of Short Stature because of Being Born SGA}

Failure to achieve sufficient catch-up growth to reach a normal height may be associated with psychosocial disadvantages during both childhood and adulthood, as other causes of short stature $[29,30]$. The impact of SGA and persistent short stature on psychosocial functioning is a much-debated issue, as data are contradictory and inconclusive. One study done in children with a short stature not due to illness, hormonal deficiency, or part of a dysmorphic syndrome [30] noted a negligible impact of short stature on psychosocial function, whereas studies performed in children born SGA have reported psychosocial disadvantages and behavioural problems, as well as academic and cognitive impairments [31-34]. A relatively recent study [35] showed low values of psychomotor development and IQ in 60 children born with IUGR aged between 3 months and 16 years. Twenty-seven of these children were followed longitudinally for 1 year without any therapeutic intervention. Even those who had experienced catch-up growth did not show any significant difference for any performed test after 4 years of age. Also, the Wechsler Intelligence Scale for Children scores showed a slight worsening [35]. The impact on the IQ seems to be inherent to the condition of being small at birth and not to the growth rate. When behavioural problems are evident, psychological evaluation is appropriate. There is some evidence [36] that long-term GH treatment of individuals with a short stature who were born SGA improves the psychological performance comparable to that of normal peers.

\section{Therapy}

\section{Treatment Objectives}

The initial aim of GH therapy is to increase the height velocity (HV) and to normalize height in early childhood. The ultimate goal is to normalize adult height in patients born SGA. While there is convincing evidence that hormone therapy is effective in achieving these targets, there is still debate on how to implement this therapy to optimize safety and efficacy, while also optimizing the cost-effectiveness.

The best approach to GH therapy will vary between individuals, depending on the severity of short stature and the child's age. Moreover, therapy should be discussed at length with the child's parents to clarify their expectations and whether these are realistic in terms of clinical efficacy. Once the treatment objectives are defined, dose, duration, and schedule of therapy that offer the best balance between safety, efficacy, and cost-effectiveness must be selected [2]

Recombinant human GH (rhGH) increases HV and height SDS in patients with a short stature who were born SGA (fig. 1). rhGH treatment in short patients born SGA has a safety profile that compares well with that of rhGH in other approved indications. Analysis of outcomes for children born SGA who failed to achieve spontaneous catch-up growth demonstrated that patients receiving rhGH achieved target adult height and stature greater than those that had been predicted without therapy [37, see 47]. Furthermore, rhGH therapy is generally associated with only mild-to-moderate adverse events. Changes in insulin-to-glucose ratios have been reported, but in most patients the impaired glucose tolerance may be transient, and, in the vast majority of the patients, the glucose tolerance is not altered [38]. Glucose intolerance and type 2 diabetes have been shown to be rare during GH therapy [39].

In July 2001, the Food and Drug Administration approved $\mathrm{rhGH}$ at a dose of $66 \mu \mathrm{g} / \mathrm{kg} / \mathrm{day}$ (or $\sim 0.2 \mathrm{IU} / \mathrm{kg} /$ day based on a conversion factor of $1 \mathrm{mg}=3 \mathrm{IU}$ ) for longterm therapy of growth failure in children born SGA (less than -2 SDS) who fail to demonstrate catch-up growth by 2 years of age [40]. In Europe, the European Medicines Agency has approved rhGH at a dose of $35 \mu \mathrm{g} / \mathrm{kg} /$ day $(\sim 0.1 \mathrm{IU} / \mathrm{kg} /$ day $)$ for the treatment of growth disturbances (current height SDS less than -2.5 and parental adjusted height SDS less than -1) in short children born SGA with a birth weight and/or length below -2 SD who failed to show catch-up growth (HV SDS $<0$ during the last year) by 4 years of age or later. This approval also men- 


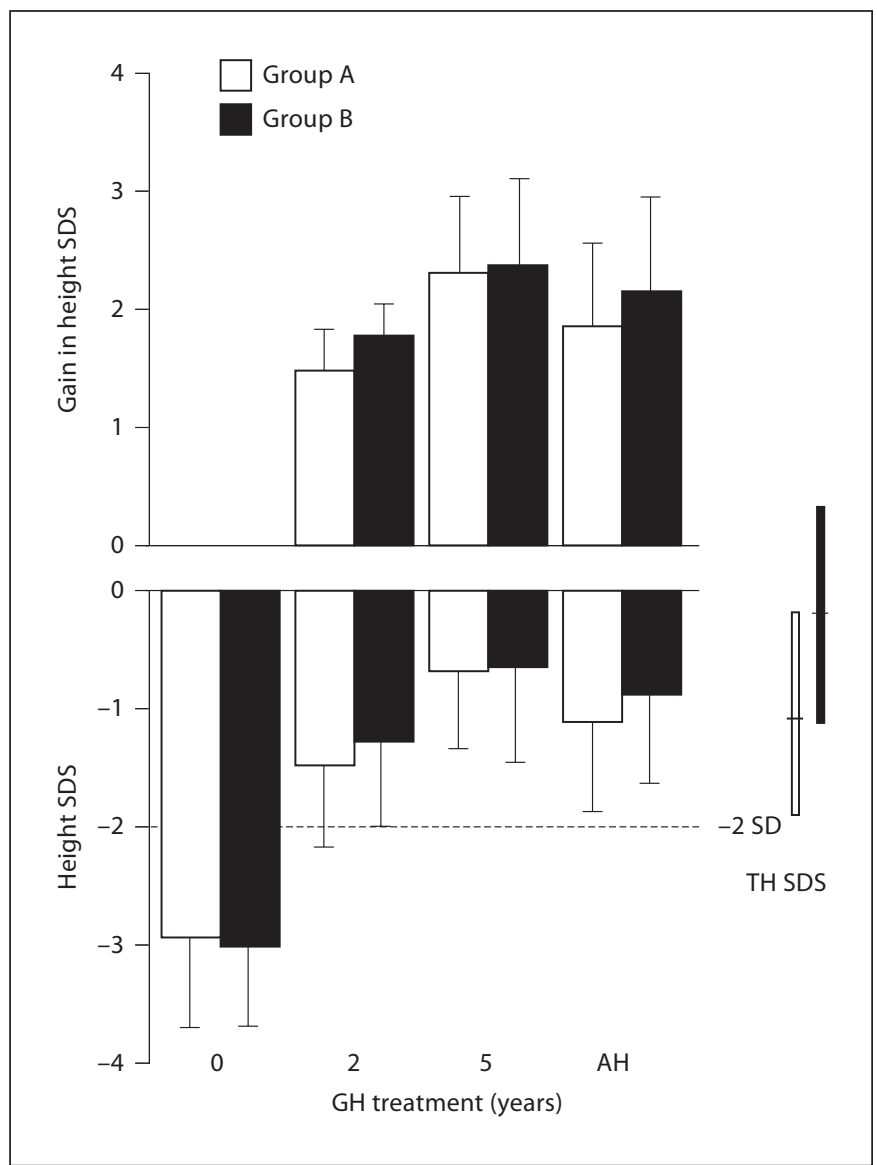

Fig. 1. Bottom panel: height $\mathrm{SDS} \pm \mathrm{SD}$ during $\mathrm{GH}$ treatment and at adult height $(\mathrm{AH})$ in relation to target height $(\mathrm{TH})$. Top panel: gain in height SDS from the start until 2 years of GH treatment, until 5 years of GH treatment, and until AH in 54 prepubertal short children born SGA and treated with rhGH. Group A: rhGH $3 \mathrm{IU} / \mathrm{m}^{2} /$ day. Group B: rhGH $6 \mathrm{IU} / \mathrm{m}^{2} /$ day. [Reproduced with permission from ref. 48.]

tions the greater efficacy of the $66-\mu \mathrm{g} / \mathrm{kg} / \mathrm{day}$ dose over that of $33 \mu \mathrm{g} / \mathrm{kg} /$ day during the 1st year of treatment [39]. The Food and Drug Administration approved dose of 66 $\mu \mathrm{g} / \mathrm{kg} /$ day is more effective in increasing HV and height during long-term treatment as compared with the lower dose of $33 \mu \mathrm{g} / \mathrm{kg} /$ day [41]. However, even though there is convincing evidence of a greater efficacy of the higher dose in the short term, other data demonstrate less benefit over the longer term [42]. The optimal individual dosing and treatment schedules for rhGH therapy cannot be considered to be fully established, largely because of diversity in clinical status, particularly with respect to the chronological age, the severity of short stature, and, possibly, endogenous GH secretion.

\section{Pretreatment Assessment}

Children with growth-restricting conditions, such as malnutrition, renal disease, skeletal dysplasia or some genetic disorders, may be born SGA. Hence, it is important that paediatricians perform a standard evaluation of children born SGA who fail to manifest catch-up growth to ensure that GH treatment is appropriate $[43,44]$. GH treatment is indicated for children who were born SGA, who have persistent short stature (less than or equal to -2 SDS for sex and population), and who are growing at a subnormal rate at the age of 3-4 years [45]. The exact European Medicines Agency indication is given above. Unless patients present with very severe forms with a diminished spontaneous catch-up growth, it is important that GH therapy is not given until the spontaneous catch-up phase is completed (2-3 years of age).

\section{Dosage}

During the 1st year of therapy, the most important predictor of growth response is the dose; higher doses at initial therapy are associated with a greater increase in HV than lower doses. In studies of children born SGA, who failed to show spontaneous catch-up growth, the dose of rhGH was found to be the most important predictor for HV $[37,46]$. Dose dependency of catch-up growth and growth acceleration following 2 years of rhGH therapy have been demonstrated in children born SGA receiving one of three treatment regimens: placebo for 6 months, $\mathrm{rhGH} 20 \mu \mathrm{g} / \mathrm{kg} / \mathrm{day}$, or rhGH $60 \mu \mathrm{g} / \mathrm{kg} /$ day for 2 years [8]. As compared with children who received the lower dose, those who received the higher dose had a greater height gain (SDS/chronological age $1.25 \pm 0.07$ in the high-dose group vs. $0.66 \pm 0.07$ in the low-dose group) and also a higher mean bone maturation progression rate over 24 months (30.2 \pm 1.5 months in the highdose group vs. $26.2 \pm 1.7$ months in the low-dose group). Interpatient variability was seen in both treatment groups, indicating that factors other than the dose of rhGH may also affect the response [8].

Significant dose-dependent catch-up growth was also demonstrated among 26 prepubertal children born SGA (mean age approximately 5 years) who received rhGH therapy (33 $\mu \mathrm{g} / \mathrm{kg} /$ day) for 1 year [47]. There were significant increases in both $\mathrm{HV}$ and height as compared with pretherapy ( $p<0.0001$ for both). After the 1st year of treatment, the patients were randomized to receive 1 further year of therapy with rhGH, either $33 \mu \mathrm{g} / \mathrm{kg} / \mathrm{day}$ $(\mathrm{n}=13)$ or $66 \mu \mathrm{g} / \mathrm{kg} / \mathrm{day}(\mathrm{n}=13)$. The increased growth rate was maintained in the patients who received the higher dose, and 11 of 13 patients achieved heights in the 
normal range ( $\geq-0.5$ SD for chronological age). Among the patients who received the lower dose, the HV was significantly slower $(p<0.015)$, leading to a significantly lower height SDS as compared with the group receiving the higher dose $(1.06 \pm 0.47$ vs. $1.58 \pm 0.46 \mathrm{SD}, \mathrm{p}<0.02)$. The investigators concluded that rhGH therapy at the higher dose induced sustained catch-up growth in children with a short stature who were born SGA. Although the significantly increased $\mathrm{HV}$ achieved over the 1st year of therapy can decrease, this can be counteracted by increasing the dose of rhGH. However, in a recent randomized study comparing the attained adult height in 55 children treated with two different GH dosages (67 or $33 \mu \mathrm{g}$ / $\mathrm{kg} /$ day), no significant difference was reached between the two groups [48]. Neither the achieved adult height nor the gain in height SDS from the start of therapy until adult height was significantly different between the two groups [49]. Similarly, de Zegher and Hokken-Koelega [42] recently demonstrated that height gain is less dose dependent over the long term than over the short term.

Based on data available up to 2001, the International SGA Advisory Board recommended the initiation of rhGH therapy at $0.48 \mathrm{mg} / \mathrm{kg} /$ week, a dose that is equivalent to the $66-\mu \mathrm{g} / \mathrm{kg} /$ day dose approved by the Food and Drug Administration (July, 2001), and the greater efficacy of the $0.48-\mathrm{mg} / \mathrm{kg} /$ week dose is quoted in the European Medicines Agency approval label for this indication [2]. The 2006 consensus meeting of the International Societies of Paediatric Endocrinology and the Growth Hormone Research Society concluded that a dose of $35-70 \mu \mathrm{g} / \mathrm{kg} /$ day should be considered [3]. Importantly, rhGH is not associated with significant adverse events and has been given for up to 6 years without any major safety issues.

\section{Early Therapy}

The age at which therapy is initiated has an important influence on the outcome of treatment. Several studies have demonstrated the benefits of beginning GH treatment early and with a high initial dose $[23,46]$. It is, therefore, important that children born SGA who have not experienced catch-up growth during the first 2 years of life are identified as early as possible. Some children who are born SGA are identified when they are young, but are not recognized as short for their age, while others are not diagnosed as being SGA at birth until they grow older and are short according to the normal growth curve.

The Nordic Multicentre Trial [50] investigated the GH treatment of 48 prepubertal children who were born SGA and had not experienced spontaneous catch-up growth; GH deficiency was not an exclusion criterion. Following randomization, 12 children received no treatment for 2 years, 16 children received $\mathrm{rhGH} 33 \mu \mathrm{g} / \mathrm{kg} / \mathrm{day}$, and 20 children received $\mathrm{rhGH} 66 \mu \mathrm{g} / \mathrm{kg} / \mathrm{day}$ [50]. In total, 42 children completed 2 years of follow-up, and 24 children of the treatment groups remained on therapy for 3 years. The therapy was successful, significantly increasing both height and $\mathrm{HV}$ in the treated patients as compared with the controls, among whom no catch-up growth was observed. All patients treated with the higher rhGH dose who completed the 3 years of therapy achieved the target height centile. The growth response was dependent on several factors: the dose of rhGH was the most influential, but there was also a negative correlation between response to rhGH and age at the start of therapy. Children who received $\mathrm{rhGH}$ at the higher dose $(66 \mu \mathrm{g} / \mathrm{kg} / \mathrm{day})$ achieved their target centile within 3 years of therapy, without significant adverse events.

Analysis of data from KIGS (Kabi-Pharmacia International Growth Study database) [46], which included data from 613 children born SGA who failed to manifest spontaneous catch-up growth, revealed that the age at which GH therapy was started was second only to dosage as the most important predictor for response. During the 1st year of therapy, the response to GH correlated negatively with age at initiation of treatment. The treatment response during the 2 nd year was best predicted by a threeparameter model: HV during the 1st year of treatment, age at the start of treatment, and rhGH dose. The study confirmed the superior efficacy of beginning therapy earlier and with higher doses of rhGH treatment as compared with delaying therapy or using lower doses. This negative correlation between age at the start of treatment and increased growth treatment response was also demonstrated after a 6-year treatment schedule [41].

Although GH increases height SDS in adolescents with a short stature who were born SGA, and although the increase is greater the longer the treatment duration [13], these data indicate that GH therapy is even more effective when it is started in younger children who do not achieve catch-up growth. The relationship between early treatment and increased height SDS may be related to the smaller height deficit in younger children than in older children and adolescents. The low number of adverse events associated with early treatment, even at high doses, indicates that the treatment can increase height SDS without giving rise to serious short-term safety concerns.

\section{Continuous versus Discontinuous Therapy}

In addition to dosage and age at which GH treatment is started, the response also varies according to the treat- 
ment schedule. Debate continues over the relative benefits of continuous versus discontinuous therapy. An epianalysis of 6-year growth responses after rhGH treatment [41] included data from four randomized multicentre studies using varied therapy schedules to treat children with short stature who were born SGA (fig. 2). Two of the studies that concentrated on continuous treatment with $\mathrm{rhGH}$ at a dose of 33 or $67 \mu \mathrm{g} / \mathrm{kg} /$ day for 6 years resulted in increased height increments of $2.0 \pm 0.2 \mathrm{SD}$ with 33 $\mu \mathrm{g} / \mathrm{kg} / \mathrm{day}(\mathrm{n}=35)$ and of $2.7 \pm 0.2 \mathrm{SD}$ with $67 \mu \mathrm{g} / \mathrm{kg} / \mathrm{day}$ $(\mathrm{n}=27)$. Among 77 patients receiving discontinuous rhGH therapy (33-100 $\mu \mathrm{g} / \mathrm{kg} /$ day), most of them underwent either one $(n=47)$ or two $(n=26)$ treatment phases of an average duration of 2.0 years; off-therapy phases lasted 1-2 years. The average dose over 6 years was 32 $\mu \mathrm{g} / \mathrm{kg} /$ day.

The dose of rhGH was particularly important in the short-term response to treatment; rapid normalization of height was achieved with the high doses of rhGH. HV and height increments were both greater following treatment with GH $67 \mu \mathrm{g} / \mathrm{kg} /$ day than with $33 \mu \mathrm{g} / \mathrm{kg} /$ day. The height SDS was similar using an early high-dose rhGH regimen given for 2 years or using a continuous low-dose regimen over 6 years. It is worth noting that interruption of therapy during discontinuous treatment was associated with decelerated growth (catch-down growth). Both doses of rhGH were effective in children with short stature who were born SGA, and the data suggest that the cumulative dose of rhGH is more important than the dosing regimen. Clinically, no safety concerns (such as related to rhGH-dose) were identified during the observation period.

Recent studies indicate that continuous therapy may be more effective than discontinuous therapy in longterm GH treatment, as interruption is associated with an overall reduction in HV. A 4-year study [51] compared 2 years of therapy $(\mathrm{T})$ followed by 2 years of observation (O) (TTOO) with 4 years of alternating between 1 year of therapy and 1 year of observation (TOTO). Generally, for both regimens, HV and HV SDS increased during treatment, but decreased during the observation phases. A transient, but significant, catch-down growth was observed: the HV SDS fell below the baseline level 1 year after interruption of treatment. This observation has also been reported in a different study [52] and indicates that continuous GH therapy, or discontinuous therapy with only short treatment breaks, should be used, at least until puberty. Both treatment regimens effectively increased growth in children born SGA; the interruption of treatment during the 2 nd year of the TOTO regimen

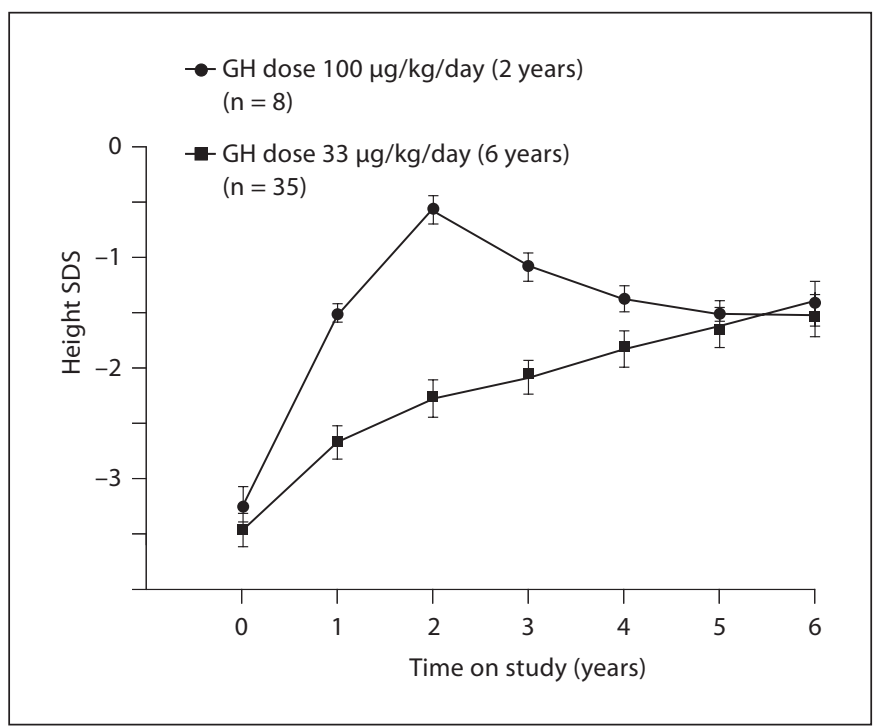

Fig. 2. Height SDS \pm SD in short children born SGA and treated with either early high-dose $\mathrm{GH}$ or with a continuous low-dose GH regimen. Height SDS after 6 years were similar with an early highdose course of GH for 2 years and with continuous low-dose GH treatment for 6 years. However, the latter regimen required threefold more injections and nearly $50 \%$ more GH. [Reproduced with permission from ref. 41.]

did not have a significant impact on the outcome as compared with the TTOO regimen. There were no differences in safety and tolerability, and there were no significant safety concerns associated with continuous therapy.

The effect of treatment interruption following 3 years of GH therapy was investigated by Fjellestad-Paulsen et al. [52] in a 5-year follow-up study (fig. 3). One year after discontinuation of treatment, there was evidence of $\mathrm{HV}$ deceleration, and HV SDS decreased dramatically, particularly during the early phase of the observation period. In addition, mean height SDS for age following 5 years off treatment was less than that at the end of therapy $(-2.2 \pm$ 1.2 vs. $-1.3 \pm 0.8$ ), although still higher than that before therapy. The investigators recommended that future regimens should be either continuous or discontinuous, with short intervals of discontinuation, at least until puberty. Finally, treatment objectives should aim at targeting an optimum height SDS before puberty, as a study during puberty has shown an only moderate (but significant) increase in height SDS [13].

In another study of 79 short SGA children treated with rhGH 1 or $2 \mathrm{mg} / \mathrm{m}^{2} /$ day (approximating to 36 or $72 \mu \mathrm{g} /$ $\mathrm{kg} /$ day for a body composition within the normal range) 
for 5 years [23], almost all achieved a normal height at the end of therapy. Among 54 children who had reached their adult height after long-term therapy with rhGH (33 or 67 $\mu \mathrm{g} / \mathrm{kg} /$ day), more than $85 \%$ had normal adult height after a mean continuous treatment period of 7.8 years [51]. Long-term continuous therapy of children with a short stature born SGA can promote catch-up growth to normal adult height.

In the first randomized, controlled prospective-toadult height open study of 168 adolescents with a short stature born SGA, the effect of continuous GH treatment was compared with no treatment [13]. In the per-protocol analysis, 91 of 102 patients in the treatment group and 33 of 47 patients in the control group were followed to adult height. Following a mean treatment duration of $2.7 \pm 0.6$ years, there was a significant difference in adult height SDS (controls $-2.7 \pm 0.9$ SDS versus treatment group $-2.1 \pm$ 1.0 SDS; $\mathrm{p}<0.005)$. The gain in height also differed between the two groups. In the control group, the height increased by $0.5 \pm 0.8 \mathrm{SDS}$; in the treatment group, the height increased by $1.1 \pm 0.9$ SDS $(p=0.002)$. GH treatment significantly increased adult height as compared with no treatment in this randomized population. Metaanalysis demonstrated that the outcome improved with treatment duration. Interestingly, but not surprisingly, the study also showed that even non-treated children presenting with a marked delay in bone age experienced a limited spontaneous catch-up growth. A delay in bone age is not a reliable predictor of residual growth potential in children born SGA and should, therefore, not be used to predict adult height, as is often the case in clinical practice [2].

An independent, international SGA Advisory Board [2] and the 2006 consensus meeting of the International Societies of Paediatric Endocrinology and the Growth Hormone Research Society [3] both developed a consensuses for management of short children who were born SGA. Therapy was recommended for short children born SGA who do not manifest spontaneous catch-up growth by the age of $2-4$ years. It was concluded that therapy with $\mathrm{GH}$ is effective and safe.

\section{Individualized Therapy in Short Patients Born SGA: the Ultimate Goal}

We believe it is acknowledged that GH therapy is effective and well tolerated, that there is a high degree of interpatient variability, and that it is difficult to predict how a given patient will respond to therapy. However, some predictors have been recognized and, by the use of a SGA prediction model, can be used to identify patients who are likely to respond to GH therapy [45].

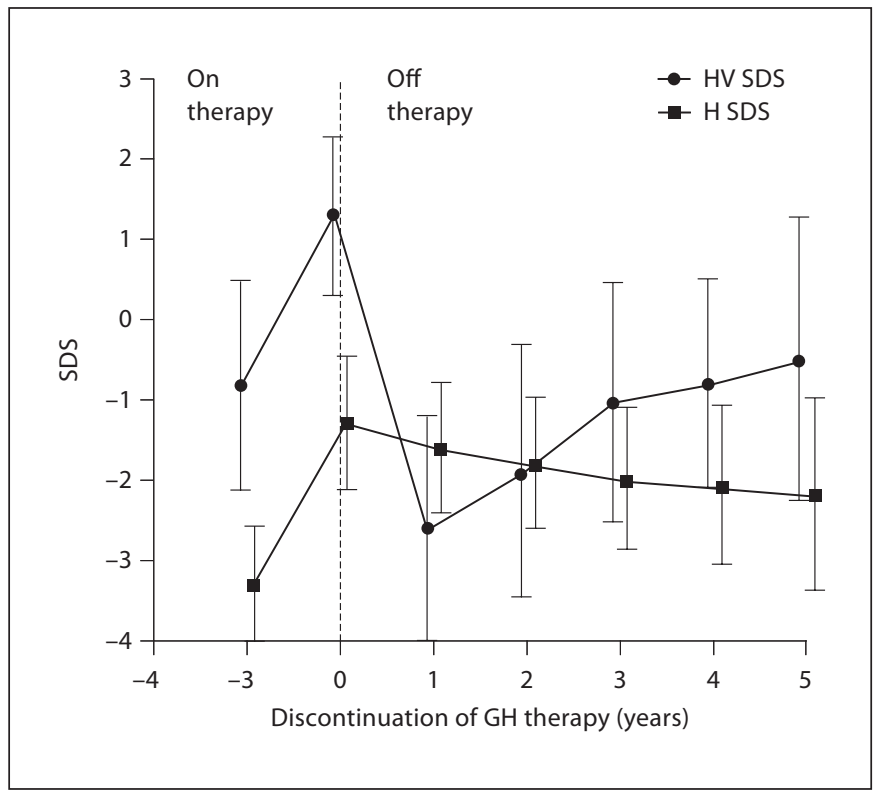

Fig. 3. Effect of GH discontinuation after 3 years of continuous treatment. Variations in height velocity SDS (HV SDS) and height SDS (H SDS) in 62 children during 3 years of therapy with human $\mathrm{GH}$ and 5 years after discontinuation of therapy [52]. Values are mean $\pm \mathrm{SD}$.

Of particular interest is a common polymorphism of the $\mathrm{GH}$ receptor gene which has been implicated as a potential modulator and hence a predictor of response. Among short children who were treated with GH, those in whom exon 3 of the GH receptor gene was deleted (hetero- or homozygous) experienced much greater growth acceleration than children with the full-length isoform ( $\mathrm{p}<0.0001)$ [53]. Additionally, transfection experiments showed a $30 \%$ reduction in $\mathrm{GH}$ signalling with full-length polymorphism homodimers as compared with homo- or heterodimers of the shorter gene. Approximately half of Europeans are homo- or heterozygous for the polymorphism that lacks exon 3. Similarly, polymorphisms have been shown to contribute to other differences in hormonal sensitivity, such as to insulin [54]. Identification of this GH receptor polymorphism and other predictors may prove important for tailoring treatment to individual patients; an approach that warrants further investigation.

\section{Safety Considerations}

Continuous GH therapy has been used without serious adverse events to achieve a normal height in children with short stature who were born SGA. Treatment with 
GH was also associated with slightly accelerated bone maturation [8].

Studies of GH therapy in short patients born SGA document the safety of GH in this patient group. Currently, no new specific adverse events have emerged from these studies. Furthermore, when the SGA studies are analyzed, the $\mathrm{GH}$ dose is not observed to influence either the prevalence or the severity of adverse events. From the data available to date, the tolerability of GH in short patients born SGA appears to be as good as in other approved indications. However, because of increased prevalence of metabolic syndrome in adults who were born SGA [27], specific attention must be paid to glucose homoeostasis and weight for height in short patients born SGA treated with GH. This should be mandatory, if the family history is positive for type 2 diabetes, obesity, or both, as these two conditions present with insulin resistance. However, GH treatment tends to normalize the body composition, increasing muscle mass with a simultaneous decrease in fat mass, the typical well-known effects of GH $[23,55]$. There is an ongoing debate regarding the acceptable level of IGF-I in GH-sufficient patients treated with $\mathrm{GH}$. On the one hand, a high level of IGF-I is associated with increased prevalence of some malignancies in adults $[56,57]$. On the other hand, high levels of IGF-binding protein-3 are associated with a decreased prevalence of the same malignancies in adults $[58,59]$. From the large, worldwide experience of GH treatment captured in outcome research databases, GH treatment does not appear to be associated with an increased risk of malignancy [60-63]. Nevertheless, it would seem appropriate to monitor IGF-I in individuals on a long-term basis, particularly in those receiving high-dose GH. There is no consensus regarding an acceptable upper limit for IGF-I. Levels such as 2.5-3.0 SDS for age have been suggested [2], but there are no long-term data for such levels, and a more conservative and probably equally efficacious limit would be 1.5-2.0 SDS.

\section{Conclusions}

Although most children with a short stature who were born SGA will experience catch-up growth leading to normal adult height, about $10-15 \%$ will have a persistent short stature. Individuals who are below normal height for their age can suffer psychosocial disadvantages throughout childhood and adulthood. To achieve a normal stature, catch-up growth can be achieved by GH treatment which has been shown to be both effective and well tolerated. Despite the success that has been achieved

with GH therapy, the optimal schedule and regimen for the ultimate goal of individual therapy of children who were born SGA and have persistent short stature have yet to be established fully.

The efficacy of GH treatment is dose dependent, with the higher dose of $66 \mu \mathrm{g} / \mathrm{kg} / \mathrm{day}$ leading to a rapid normalization of height; however, long-term therapy with lower doses can achieve clinically meaningful gains in height at follow-up. At present, we cannot reconcile why greater short-term efficacy is seen with high-dose GH, but that this is not the case in the long term. It would be helpful if this difference could be understood, and future studies should address this question. In addition to dose, starting treatment early is also associated with improved outcome. Various studies have also compared the efficacy of continuous therapy with that of discontinuous therapy. Long-term continuous treatment is effective, even at a dose of $25 \mu \mathrm{g} / \mathrm{kg} /$ day. To minimize the deceleration (catch-down growth) observed when treatment is stopped before adult height, therapy should be continuous or should include only brief periods of discontinuation.

The increasing amount of good-quality data on GH therapy that are available will aid the development of optimal treatment regimens, perhaps by combining early implementation of higher-dose rhGH therapy, followed by long-term maintenance with a reduced dose. In addition, identification of efficacy and risk factors that can be used to predict the responses of patients to therapy will lead to the development of treatment regimens tailored to suit individual patients - the ultimate goal of GH therapy of short children born SGA.

References

$$
\begin{aligned}
& 1 \text { de Zegher F, Francois I, Van Helvoit M, Beck- } \\
& \text { ers D, Ibáñez L, Chatelain P: Growth hor- } \\
& \text { mone treatment of short children born small } \\
& \text { for gestational age. Trends Endocrinol Metab } \\
& \text { 1998;9:233-237. } \\
& \text { Lee PA, Chernausek SD, Hokken-Koelega } \\
& \text { AC, Czernichow P, International Small for } \\
& \text { Gestational Age Advisory Board: Interna- } \\
& \text { tional Small for Gestational Age Advisory } \\
& \text { Board consensus development conference } \\
& \text { statement: management of short children } \\
& \text { born small for gestational age, April 24-Oc- } \\
& \text { tober 1, 2001. Pediatrics 2003;111(6 Pt 1): } \\
& \text { 1253-1261. } \\
& \text { Clayton PE, Cianfarani S, Czernichow P, Jo- } \\
& \text { hannsson G, Rapaport R, Rogol A: Manage- } \\
& \text { ment of the child born small for gestational } \\
& \text { age through to adulthood: a consensus state- } \\
& \text { ment of the International Societies of Pediat- } \\
& \text { ric Endocrinology and the Growth Hormone } \\
& \text { Research Society. J Clin Endocrinol Metab } \\
& \text { 2007;92:804-810. }
\end{aligned}
$$


-4 Martin JA, Hamilton BE, Ventura SJ, Menacker F, Park MM: Births: final data for 2000. Natl Vital Stat Rep 2002;50:1-101.

5 Hediger ML, Overpeck MD, Maurer KR, Kuczmarski RJ, McGlynn A, Davis WW: Growth of infants and young children born small or large for gestational age: findings from the Third National Health and Nutrition Examination Survey. Arch Pediatr Adolesc Med 1998;152:1225-1231.

6 Usher R, McLean F: Intrauterine growth of live-born Caucasian infants at sea level: standards obtained from measurements in 7 dimensions of infants born between 25 and 44 weeks of gestation. J Pediatr 1969;74:901910.

$\checkmark 7$ Lee PA, Blizzard RM, Cheek DB, Holt AB: Growth and body composition in intrauterine growth retardation (IUGR) before and during human growth hormone administration. Metabolism 1974;23:913-919.

8 Chatelain P, Job JC, Blanchard J, Ducret JP, Oliver M, Sagnard L, VanderschuerenLodeweyckx M: Dose-dependent catch-up growth after 2 years of growth hormone treatment in intrauterine growth-retarded children. Belgian and French Pediatric Clinics and Sanofi-Choay (France). J Clin Endocrinol Metab 1994;78:1454-1460.

$\checkmark 9$ Boersma B, Wit JM: Catch-up growth. Endocr Rev 1997;18:646-661.

10 Hokken-Koelega AC, De Ridder MA, Lemmen RJ, Den Hartog H, de Muinck KeizerSchrama SM, Drop SL: Children born small for gestational age: do they catch up? Pediatr Res 1995;38:267-271.

-11 Karlberg J, Albertsson-Wikland K: Growth in full-term small-for-gestational-age infants: from birth to final height. Pediatr Res 1995;38:733-739.

-12 Leger J, Levy-Marchal C, Bloch J, Pinet A, Chevenne D, Porquet D, Collin D, Czernichow P: Reduced final height and indications for insulin resistance in 20 year olds born small for gestational age: regional cohort study. BMJ 1997;315:341-347.

$\checkmark 13$ Carel JC, Chatelain P, Rochiccioli P, Chaussain JL: Improvement in adult height after growth hormone treatment in adolescents with short stature born small for gestational age: results of a randomized controlled study. J Clin Endocrinol Metab 2003;88:15871593.

-14 Jaquet D, Collin D, Levy-Marchal C, Czernichow P: Adult height distribution in subjects born small for gestational age. Horm Res 2004;62:92-96.

15 Gluckman PD: Clinical review 68: the endocrine regulation of fetal growth in late gestation: the role of insulin-like growth factors. J Clin Endocrinol Metab 1995;80:1047-1050.

16 Le Roith D: Seminars in medicine of the Beth Israel Deaconess Medical Center. Insulinlike growth factors. N Engl J Med 1997;336: 633-640.
17 DeChiara TM, Efstratiadis A, Robertson EJ: A growth deficiency phenotype in heterozygous mice carrying an insulin-like growth factor II gene disrupted by targeting. Nature 1990;345:78-80.

18 Deiber M, Chatelain P, Naville D, Putet G, Salle B: Functional hypersomatotropism in small for gestational age (SGA) newborn infants. J Clin Endocrinol Metab 1989;68:232234

19 de Waal WJ, Hokken-Koelega AC, Stijnen T, de Muinck Keizer-Schrama SM, Drop SL: Endogenous and stimulated GH secretion, urinary GH excretion, and plasma IGF-I and IGF-II levels in prepubertal children with short stature after intrauterine growth retardation. The Dutch Working Group on Growth Hormone. Clin Endocrinol (Oxf) 1994;41:621-630.

20 Boguszewski M, Bjarnason R, Jansson C, Rosberg S, Albertsson-Wikland K: Hormonal status of short children born small for gestational age. Acta Paediatr Suppl 1997;423: 189-192.

21 Albertsson-Wikland K: Growth hormone secretion and growth hormone treatment in children with intrauterine growth retardation. Swedish Paediatric Study Group for Growth Hormone Treatment. Acta Paediatr Scand Suppl 1989;349:35-41, discussion 5354.

22 Boguszewski M, Jansson C, Rosberg S, Albertsson-Wikland K: Changes in serum insulin-like growth factor I (IGF-I) and IGFbinding protein-3 levels during growth hormone treatment in prepubertal short children born small for gestational age. J Clin Endocrinol Metab 1996;81:3902-3908.

23 Sas T, de Waal W, Mulder P, Houdijk M, Jansen M, Reeser M, Hokken-Koelega AC: Growth hormone treatment in children with short stature born small for gestational age: 5 -year results of a randomized, double-blind, dose-response trial. J Clin Endocrinol Metab 1999;84:3064-3070.

-24 Curhan GC, Willett WC, Rimm EB, Spiegelman D, Ascherio AL, Stampfer MJ: Birth weight and adult hypertension, diabetes mellitus, and obesity in US men. Circulation 1996;94:3246-3250.

25 Ong KK, Dunger DB: Perinatal growth failure: the road to obesity, insulin resistance and cardiovascular disease in adults. Best Pract Res Clin Endocrinol Metab 2002;16: 191-207.

26 Yarbrough DE, Barrett-Connor E, Kritz-Silverstein D, Wingard DL: Birth weight, adult weight, and girth as predictors of the metabolic syndrome in postmenopausal women: the Rancho Bernardo Study. Diabetes Care 1998;21:1652-1658.

27 Barker DJ, Hales CN, Fall CH, Osmond C, Phipps K, Clark PM: Type 2 (non-insulin-dependent) diabetes mellitus, hypertension and hyperlipidaemia (syndrome $\mathrm{X}$ ): relation to reduced fetal growth. Diabetologia 1993; 36:62-67.
28 Hofman PL, Cutfield WS, Robinson EM, Bergman RN, Menon RK, Sperling MA, Gluckman PD: Insulin resistance in short children with intrauterine growth retardation. J Clin Endocrinol Metab 1997;82:402406.

29 Stabler B, Siegel PT, Clopper RR, Stoppani CE, Compton PG, Underwood LE: Behavior change after growth hormone treatment of children with short stature. J Pediatr 1998; 133:366-373.

30 Kranzler JH, Rosenbloom AL, Proctor B, Diamond FB Jr, Watson M: Is short stature a handicap? A comparison of the psychosocial functioning of referred and nonreferred children with normal short stature and children with normal stature. J Pediatr 2000;136: 96-102.

-31 McCarton CM, Wallace IF, Divon M, Vaughan HG Jr: Cognitive and neurologic development of the premature, small for gestational age infant through age 6: comparison by birth weight and gestational age. Pediatrics 1996;98:1167-1178.

32 Paz I, Gale R, Laor A, Danon YL, Stevenson DK, Seidman DS: The cognitive outcome of full-term small for gestational age infants at late adolescence. Obstet Gynecol 1995;85: 452-456.

33 Larroque B, Bertrais S, Czernichow P, Leger J: School difficulties in 20-year-olds who were born small for gestational age at term in a regional cohort study. Pediatrics 2001;108: 111-115.

34 Lundgren EM, Cnattingius S, Jonsson B, Tuvemo T: Intellectual and psychological performance in males born small for gestational age with and without catch-up growth. Pediatr Res 2001;50:91-96.

35 Puga B, Ferrández Longás A, García Romero R, Mayayo E, Labarta JI: Psychomotor and intellectual development of children born with intrauterine growth retardation (IUGR). J Pediatr Endocrinol Metab 2004; 17(Suppl 3):457-462.

36 van Pareren YK, Duivenvoorden HJ, Slijper FS, Koot HM, Hokken-Koelega AC: Intelligence and psychosocial functioning during long-term growth hormone therapy in children born small for gestational age. J Clin Endocrinol Metab 2004;89:5295-5302.

37 Ranke MB, Lindberg A: Growth hormone treatment of short children born small for gestational age or with Silver-Russell syndrome: results from KIGS (Kabi International Growth Study), including the first report on final height. Acta Paediatr Suppl 1996; 417:18-26.

38 van Pareren YK, Mulder P, Houdijk M, Jansen M, Reeser M, Hokken-Koelega AC: Effect of discontinuation of growth hormone treatment on risk factors for cardiovascular disease in adolescents born small for gestational age. J Clin Endocrinol Metab 2003;88: 347-353. 
-39 Cutfield WS, Wilton P, Bennmarker H, Albertsson-Wikland $\mathrm{K}$, Chatelain $\mathrm{P}$, Ranke $\mathrm{MB}$, Price DA: Incidence of diabetes mellitus and impaired glucose tolerance in children and adolescents receiving growth hormone treatment. Lancet 2000;355:610-613.

40 Czernichow P: Growth hormone treatment strategy for short children born small for gestational age. Horm Res 2004;62(Suppl 3): 137-140.

-41 de Zegher F, Albertsson-Wikland K, Wollmann HA, Chatelain P, Chaussain JL, Löfström A, Jonsson B, Rosenfeld RG: Growth hormone treatment of short children born small for gestational age: growth responses with continuous and discontinuous regimens over 6 years. J Clin Endocrinol Metab 2000;85:2816-2821.

-42 de Zegher F, Hokken-Koelega A: Growth hormone therapy for children born small for gestational age: height gain is less dose dependent over the long term than over the short term. Pediatrics 2005;115:458-462.

43 Brook C: Short stature; in Brook CG (ed): Clinical Paediatric Endocrinology. Oxford, Blackwell, 1995.

44 Reiter EO, Rosenfeld RG: Normal and aberrant growth; in Wilson JD, Foster DW, Kronenberg HM, Larsen PR (eds): Williams Textbook of Endocrinology. Philadelphia, Saunders, 1998, pp 1427-1507.

-45 Rapaport R: Growth and growth hormone in children born small for gestational age. Growth Horm IGF Res 2004; 14(Suppl A): S3-S6.

-46 Ranke MB, Lindberg A, Cowell CT, Wikland KA, Reiter EO, Wilton P, Price DA; KIGS International Board: Prediction of response to grow th hormone treatment in short children born small for gestational age: analysis of data from KIGS (Pharmacia International Growth Database). J Clin Endocrinol Metab 2003;88:125-131.

-47 Bozzola E, Lauriola S, Messina MF, Bona G, Tinelli C, Tato L: Effect of different growth hormone dosages on the growth velocity in children born small for gestational age. Horm Res 2004;61:98-102.
48 van Pareren YK, Mulder P, Houdijk M, Jansen M, Reeser M, Hokken-Koelega AC: Adult height after long-term, continuous growth hormone $(\mathrm{GH})$ treatment in short children born small for gestational age: results of a randomized, double-blind, dose-response GH trial. J Clin Endocrinol Metab 2003;88: 3584-3590.

49 Hokken-Koelega AC, de Waal WJ, Sas TC, van Pareren YK, Arends NJ: Small for gestational age (SGA): endocrine and metabolic consequences and effects of growth hormone treatment. J Pediatr Endocrinol Metab 2004;17(Suppl 3):463-469.

50 Boguszewski M, Albertsson-Wikland K, Aronsson S, Gustafsson J, Hagenäs L, Westgren U, Westphal O, Lipsanen-Nyman M, Sipilä I, Gellert P, Müller J, Madsen B: Growth hormone treatment of short children born small-for-gestational-age: the Nordic Multicentre Trial. Acta Paediatr 1998;87:257-263.

51 Simon D, Leger J, Fjellestad-Paulsen A, Crabbé R, Czernichow P; SGA Study Group: Intermittent recombinant growth hormone treatment in short children born small for gestational age: 4-year results of a randomized trial of two different treatment regimens. Horm Res 2006;66:118-123.

52 Fjellestad-Paulsen A, Simon D, Czernichow P: Short children born small for gestational age and treated with growth hormone for three years have an important catch-down five years after discontinuation of treatment. J Clin Endocrinol Metab 2004;89:12341239.

53 Dos Santos C, Essioux L, Teinturier C, Tauber M, Goffin V, Bougnères P: A common polymorphism of the growth hormone receptor is associated with increased responsiveness to growth hormone. Nat Genet 2004;36:720-724.

54 Le Stunff C, Fallin D, Schork NJ, Bougnères $\mathrm{P}$ : The insulin gene VNTR is associated with fasting insulin levels and development of juvenile obesity. Nat Genet 2000;26:444-446.
55 Leger J, Carel C, Legrand I, Paulsen A, Hassan M, Czernichow P: Magnetic resonance imaging evaluation of adipose tissue and muscle tissue mass in children with growth hormone $(\mathrm{GH})$ deficiency, Turner's syndrome, and intrauterine growth retardation during the first year of treatment with GH. J Clin Endocrinol Metab 1994;78:904-909.

56 Pollak M: Insulin-like growth factor physiology and neoplasia. Growth Horm IGF Res 2000;10(Suppl A):S6-S7.

57 Ma J, Pollak MN, Giovannucci E, Chan JM, Tao Y, Hennekens CH, Stampfer MJ: Prospective study of colorectal cancer risk in men and plasma levels of insulin-like growth factor (IGF)-I and IGF-binding protein-3. J Natl Cancer Inst 1999;91:620-625.

58 Baxter RC, Butt AJ, Schedlich LJ, Martin JL: Antiproliferative and pro-apoptotic activities of insulin-like growth factor-binding protein-3. Growth Horm IGF Res 2000; 10(Suppl A):S10-S11.

59 Martin JL, Baxter RC: Oncogenic ras causes resistance to the growth inhibitor insulinlike growth factor binding protein-3 (IGFBP3) in breast cancer cells. J Biol Chem 1999; 274:16407-16411.

60 Tuffli GA, Johanson A, Rundle AC, Allen DB: Lack of increased risk for extracranial, nonleukemic neoplasms in recipients of recombinant deoxyribonucleic acid growth hormone. J Clin Endocrinol Metab 1995;80: 1416-1422.

61 Allen DB, Rundle AC, Graves DA, Blethen SL: Risk of leukemia in children treated with human growth hormone: review and reanalysis. J Pediatr 1997;131(1 Pt 2):S32-S36.

62 Howell SJ, Wilton P, Lindberg A, Shalet SM: Growth hormone replacement and the risk of malignancy in children with neurofibromatosis. J Pediatr 1998;133:201-205.

63 Price DA, Wilton P, Jonsson P, AlbertssonWikland K, Chatelain P, Cutfield W, Ranke MB: Efficacy and safety of growth hormone treatment in children with prior craniopharyngioma: an analysis of the Pharmacia and Upjohn International Growth Database (KIGS) from 1988 to 1996. Horm Res 1998; 49:91-97. 